\title{
Efectos neurotóxicos del timerosal, a dosis de vacuna, sobre el encéfalo y el desarrollo en hámsteres de 7 días de nacidos
}

\author{
Jonny Laurente ${ }^{1}$, Fany Remuzgo ${ }^{1}$, Betthina Ávalos ${ }^{1}$, Johnnie Chiquinta ${ }^{1}$, \\ Bladimir Ponce ${ }^{1}$, Ronald Avendaño ${ }^{1}$, Luis Maya ${ }^{2,3}$
}

Resumen

Objetivos: Determinar si la administración de timerosal, en cantidades equivalentes al contenido en las vacunas, produce efectos neurotóxicos a nivel encefálico en hámsteres de 7 días de nacidos y evaluar las influencias sobre el desarrollo de los animales de experimentación. Diseño: Estudio experimental, prospectivo y bietápico. Lugar: Bioterio de la Facultad de Medicina de San Fernando, Universidad Nacional Mayor de San Marcos. Material biológico: Hámsteres de 7 días de nacidos. Métodos: Se estudió 45 hámsteres divididos en tres grupos: grupo $A(n=15)$, grupo $B(n=15)$ y grupo $C(n=15)$. Se administró a los grupos $B$ y $C$, por vía intramuscular, 3 dosis equivalentes de sucrosa y timerosal, respectivamente, los días 7 (0,227 $\mu \mathrm{g}), 9(0,216 \mu \mathrm{g})$ y $11(0,220 \mu \mathrm{g})$ de nacimiento, en un volumen de $20 \mu \mathrm{L}$ de suero fisiológico. El grupo A solo recibió igual cantidad de suero fisiológico en los mismos días. Principales medidas de resultados: Peso corporal, peso encefálico, talla de los hámsteres y alteraciones histopatólógicas encefálicas. Resultados: Las pruebas Anova y t de student fueron significativas en favor al menor peso corporal, menor peso encefálico y menor talla del grupo $C$ con respecto a los grupos $A$ y $B(p<0,000)$. Mediante $\chi 2$, se obtuvo significancia en relación a la presencia de alteraciones histopatológicas en el grupo $C(p<0,000)$. El RR de presentar alteraciones fue muy elevado en este grupo. Conclusiones: La exposición a timerosal, en cantidades equivalentes al contenido en las vacunas, disminuyó de manera significativa el peso corporal, el peso encefálico y la talla de hámsteres posnatales. Asimismo, produjo efectos neurotóxicos a nivel encefálico, encontrándose a nivel del hipocampo (regiones $C A 1, C A 3, D G$ ), corteza cerebral y cerebelo (células de Purkinje y células granulosas) disminución de la densidad neuronal, necrosis neuronal, desmielinización axonal y gliosis; además, el riesgo de presentar alguna de estas alteraciones fue muy elevado en el grupo de animales que recibió timerosal.

Palabras clave Vacunas; timerosal; mesocricetus; compuestos de etilmercurio; intoxicación del sistema nervioso por mercurio.

\section{Neurotoxic effects of thimerosal at vaccines doses on the encephalon and development in $\mathbf{7}$ day-old hamsters}

\footnotetext{
Abstract

Objectives: To determine if thimerosal administration in amounts equivalent to vaccines content produces neurotoxic effects on the encephalon in postnatal hamsters and on experimentation animals' development. Design: Experimental, prospective, bietapic study. Setting: San Fernando Faculty of Medicine, Universidad Nacional

1 Estudiantes de Medicina, Facultad de Medicina - Universidad Nacional Mayor de San Marcos. Lima, Perú.

2 Profesor del Departamento de Medicina, Facultad de Medicina Universidad Nacional Mayor de San Marcos. Lima, Perú.

3 Médico Internista, Hospital Nacional Arzobispo Loayza. Lima, Perú.
}

Mayor de San Marcos. Biologic material: Seven-day old hamsters. Material: We divided 45 postnatal hamsters in three groups: group $A(n=15)$, group $B(n=15)$ and group $C(n=15)$. We administered three intramuscular equivalent doses of sucrose and thimerosal in $20 \mu \mathrm{L}$ of physiological serum respectively to groups $B$ and $C$ on birth-days $7(0,227 \mu \mathrm{g}), 9(0,216 \mu \mathrm{g})$ and $11(0,220 \mu \mathrm{g})$. Group A received only $20 \mu \mathrm{L}$ of saline solution. Main outcome measures: Body weight, encephalon weight, hamster's stature and encephalon histopathological alterations. Results: Anova and student $t$ tests showed statistical significance in favor of low body weight, low encephalon weight and smaller stature in group $C$ with respect to groups $A$ and $B$ hamsters $(p<0,000) \cdot \chi^{2}$ statistical significance in relation to the presence of histopathological alterations in group $C$ was also obtained $(p<0,000)$. We 
observed greater relative risk of encephalic alterations in group C. Conclusions: The administration of thimerosal in doses equivalent to vaccines content was associated with low corporal weight, low encephalon weight and smaller stature in postnatal hamsters. Neurotoxic effects were also produced at encephalic level, at hippocampus (regions $C A 1, C A 3, D G$ ), cerebral cortex and cerebellum (Purkinje cells and granuloses cells) with decrease in neuronal density, neuronal necrosis, axonal dismyelinization and gliosis. In addition, risk increase in developing any of these alterations was high in the animal group receiving thimerosal.

Keywords: Vaccines; thimerosal; mesocricetuss; ethylmercury compounds; mercury poisoning, nervous system.

\section{INTRODUCCIÓN}

El impacto de las vacunas sobre la salud pública durante el siglo XX ha sido enorme. Sin duda, las inmunizaciones han sido uno de nuestros más eficaces medios para prevenir enfermedades, discapacidades y muertes, así como para reducir y controlar costos sanitarios, convirtiéndose de este modo en un arma indispensable de la sociedad moderna para combatir las enfermedades infectocontagiosas $\left({ }^{1}\right)$. Por ello, ha suscitado gran controversia el hecho de que se haya puesto en tela de juicio la seguridad y la confiabilidad de algunas vacunas, debido a los efectos que podría ocasionar el preservante timerosal (tiomersal) que contienen, el cual, luego de inyectado en el organismo, se disocia en etilmercurio (etill $\mathrm{Hg}$ ), un derivado mercurial orgánico neurotóxico $\left.{ }^{2,3}\right)$.

Durante los últimos años, múltiples trabajos han comunicado un extraordinario aumento de casos de desórdenes del neurodesarrollo infantil $\left({ }^{4-17}\right)$. Paralelamente, una creciente minoría de médicos y científicos de todo el mundo empezó a cuestionar seriamente el uso de timerosal en la vacunación infantil, relacionándolo con el aumento de la prevalencia de diversas enfermedades del neurodesarrollo, tales como los desórdenes del espectro autista (DEA) y otros problemas de la cognición $\left({ }^{12,14,15,17}\right)$. Debido a ello, múltiples instituciones han realizado sendos pronunciamientos relacionados al tema $\left({ }^{17-26}\right)$.

En los Estados Unidos de Norteamérica (EE UU), se han conducido siete grandes estudios epidemiológicos poblacionales retrospectivos, que han evaluado la asociación entre el timerosal, contenido en las vacunas pediátricas, y los DEA. De ellos, seis investigaciones encontraron que sí existía tal relación causal $\left({ }^{27-32}\right)$, incluyendo un reciente estudio de tipo metaanalítico $\left({ }^{32}\right)$; mientras que uno concluyó finalmente que no podía aceptar ni rechazar dicha hipótesis $\left({ }^{33}\right)$. Otros estudios epidemiológicos, conducidos fuera de los EE UU, no han encontrado una asociación aparente $\left({ }^{34-39}\right)$.

Kravchenko y col., trabajando con cultivos de células humanas, documentaron que el timerosal no solo era dañino por sus efectos tóxicos primarios, sino que, además, era capaz de cambiar las propiedades celulares, concluyendo que su uso en las preparaciones médicas biológicas, especialmente las dirigidas a los niños, era inadmisible $\left({ }^{40}\right)$. Luego de dicha publicación, los países soviéticos retiraron el timerosal de sus vacunas infantiles a principios de la década de los 80. Muchos otros estudios llegan a conclusiones similares, señalando la inconveniencia del timerosal en las vacunas, ya sea por su capacidad para inducir respuestas alérgicas $\left({ }^{41,42}\right)$, su pobre efectividad antiséptica $\left({ }^{43}\right)$ y/o su degradación en sustancias neurotóxicas $\left({ }^{44}\right)$.

A pesar de estas múltiples investigaciones, la US Food and Drug Administration (FDA) nunca se ha pronunciado prefiriendo las vacunas libres de timerosal sobre las que aún lo contienen; de hecho, si bien desde el año 1999 las sociedades científicas médicas y las autoridades sanitarias de los EE UU decidieron el pronto y urgente retiro de dicho preservante de sus vacunas $(22,23)$, tal proceso no se llevó a cabo sino hasta el año 2003, hecho que ha significado duras críticas por parte del propio Congreso norteamericano $\left({ }^{17}\right)$.

En el Perú, las autoridades del Ministerio de Salud (Minsa) aún continúan utilizando vacunas con un alto contenido de timerosal (cuya presentación multidosis es, hasta la fecha, usada en algunos establecimientos de salud), señalando que no tiene efectos secundarios $\left({ }^{45}\right)$. Ello ha generado un intenso cuestionamiento al Minsa por parte de la opinión pública, un sector de la comunidad médica y diversos organismos no gubernamentales. Este debate demanda que se emprenda investigaciones 
que permitan dilucidar y tomar medidas concretas respecto al tema.

Ante esta situación, optamos por desarrollar el presente estudio, el cual determinaría los posibles efectos neurotóxicos generados tras la administración de timerosal, a dosis de vacuna; particularmente las alteraciones que se evidenciarían a nivel encefálico, en un modelo de experimentación animal, así como las posibles influencias de dicha sustancia sobre el desarrollo y el crecimiento de los animales de experimentación, debido a que, por razones éticas, esta sustancia no puede ser probada en seres humanos.

\section{MÉTODOS}

Se realizó un estudio experimental, longitudinal, prospectivo y bietápico, el cual fue abordado con un enfoque cuali-cuantitativo. La población de estudio estuvo conformada por hámsteres sirio-dorados (Mesocricetus auratus) posnatales, los cuales debían de cumplir los siguientes criterios:

- Criterios de selección: hámsteres sirio-dorados posnatales $\leq$ a 7 días de nacidos, cuyo peso y talla al séptimo día fueran de 8,5 $\pm 0,5 \mathrm{~g}$ y $4,5 \pm 0,5 \mathrm{~cm}$, respectivamente, sin exposición previa a timerosal. Se excluyó a los hámsteres que, antes del estudio, presentaron anomalías y/o enfermedades determinadas.

- Criterios de retiro del estudio: hámsteres postnatales que durante el periodo de experimentación sufrieran alguna lesión grave y/o muerte, y hámsteres que no cumplieran con el esquema completo de administración de sustancias.

La muestra fue seleccionada mediante muestreo probabilístico aleatorio por conglomerados (por camada), obteniéndose 45 hámsteres posnatales, los cuales fueron distribuidos en tres grupos: grupo $\mathrm{A}$ $(n=15)$, grupo $B(n=15)$ y grupo $C(n=15)$. Para la determinación del poder y del tamaño de la muestra, se consideró $\alpha=0,05$ y $\beta=0,1$.

A los grupos B y C se les administró por vía intramuscular tres dosis equivalentes de sucrosa y timerosal, respectivamente, en los días $7(0,227$ $\mu \mathrm{g} / \mathrm{dosis}), 9(0,216 \mu \mathrm{g} /$ dosis $)$ y $11(0,220 \mu \mathrm{g} /$ dosis $)$ del nacimiento, en un volumen de $20 \mu \mathrm{L}$ de suero fisiológico. Al grupo A solo se le administró 3 dosis de $20 \mu \mathrm{L}$ de suero fisiológico, en las mismas fechas. El cálculo de las dosis se realizó en función del peso corporal y la cantidad de timerosal a la que estuvo expuesto un niño desde el nacimiento hasta los 6 meses de vida, imitando el esquema de vacunación de los EE UU del año $2001\left(^{(46)}\right.$. La cronología en la aplicación de las sustancias se basó en las analogías del desarrollo del sistema nervioso central y la maduración del sistema inmunológico entre humanos y murinos, incluyendo las etapas de migración neuronal y de tolerancia inmunológica $\left({ }^{47-49}\right)$, según se muestra en la Tabla 1. Para la administración de las sustancias, se utilizó jeringas tipo ultrafina $\mathrm{N}^{\circ} 2$ para insulina.

A los 25 días del nacimiento (tiempo estimado del metabolismo del timerosal) $\left.{ }^{(50}\right)$, se evaluó el peso y la talla de los animales de estudio; luego, se procedió a su sacrificio y a la extracción del encéfalo, que luego de ser pesado, inmediatamente después fue fijado en formol al $10 \%$. Para el procesamiento de las muestras y el estudio macro y microscópico, se utilizó diversas coloraciones

Tabla 1. Esquema de administración de sustancias.

\begin{tabular}{|c|c|c|c|}
\hline & \multicolumn{3}{|c|}{ Edad infantil (en meses) } \\
\hline & 2 & 4 & 6 \\
\hline $\begin{array}{l}\text { Edad equivalente en un } \\
\text { hámster posnatal * }^{\text {* }}\end{array}$ & Día 7 & Día 9 & Día 11 \\
\hline $\begin{array}{l}\text { Cantidad de timerosal en } \\
\text { las vacunas }(\mu g)^{\dagger}\end{array}$ & 125 & 125 & 125 \\
\hline Peso promedio de un niño (kg) & 4,4 & 5,8 & 6,8 \\
\hline Dosis de timerosal ( $\mu \mathrm{g} / \mathrm{kg})$ & 28,4 & 21,6 & 18,4 \\
\hline Grupo A & \multicolumn{3}{|c|}{ Suero fisiológico $(\mathrm{NaCl}$ al 9\%o) } \\
\hline $\begin{array}{l}\text { Grupo B } \\
\text { contenido de sucrosa a } \\
\text { administrar ( } \mu \mathrm{g} / \text { dosis) }\end{array}$ & $\begin{array}{l}\text { Suero } \\
0,227\end{array}$ & $\begin{array}{l}\text { ológico } \\
0,216\end{array}$ & $\begin{array}{l}\text { icrosa } \\
0,220\end{array}$ \\
\hline $\begin{array}{l}\text { Grupo C } \\
\text { contenido de timerosal } \\
\text { a administrar ( } \mu \mathrm{g} / \text { dosis) }\end{array}$ & $\begin{array}{l}\text { Suero } \\
0,227\end{array}$ & $\begin{array}{l}\text { lógico + } \\
0,216\end{array}$ & $\begin{array}{c}\text { nerosal } \\
0,220\end{array}$ \\
\hline $\begin{array}{l}\text { Volumen total administrado } \\
\text { de las sustancias ( } \mu \mathrm{L} / \text { dosis) }\end{array}$ & 20 & 20 & 20 \\
\hline
\end{tabular}


especiales (hematoxilina-eosina, tricrómica de Pollak, tricrómica de Gomori, luxol fast blue), a fin de determinar en forma más precisa la probable presencia de daños histopatológicos, los que fueron evaluados por un patólogo experto del Instituto de Patología de la Facultad de Medicina de San Fernando, UNMSM, quien desconocía la pertenencia de cada grupo de estudio. Para la recolección de los datos, se utilizó fichas, donde se incluyó las variables peso corporal, peso encefálico, talla y alteraciones histopatológicas a nivel encefálico.

\section{Las hipótesis a probar fueron:}

H1: la administración de timerosal, en cantidades equivalentes al contenido en las vacunas, produce efectos neurotóxicos a nivel encefálico en hámsteres posnatales, además de producir un menor desarrollo y restricción del crecimiento.

$\mathrm{H} 2$ : entre las alteraciones histopatológicas que podríamos observar a nivel encefálico estarían: disminución en la densidad neuronal, necrosis neuronal, desmielinización axonal y gliosis, principalmente.

El procesamiento estadístico se efectuó de la siguiente manera:

- Análisis de variables cuantitativas: se realizó mediante la prueba $\mathrm{F}$ (one-way Anova) para comparar las medias de los pesos corporales, pesos encefálicos y la talla de los diferentes grupos de estudio $(\alpha=0,01)$. Se utilizó la prueba $t$ de student para muestras independientes, con la finalidad de comparar las medias de los pesos corporales, pesos encefálicos y la talla, intergrupalmente, y establecer un orden de relación $(\alpha=0,01)$.

- Análisis de variables cualitativas: se usó la prueba de $X^{2}$ (chi-cuadrado), para establecer el grado de homogeneidad entre los grupos de estudio, con respecto a las alteraciones histopatológicas $(\alpha=0,01)$.

Además, se estudió comparativamente la incidencia de alteraciones encefálicas entre los grupos B y C, para establecer el grado de asociación con la exposición previa a timerosal. Se utilizó los siguientes criterios estadísticos: riesgo relativo
(RR), reducción del riesgo absoluto (diferencia de riesgos, RRA), reducción del riesgo relativo (RRR) y número de hámsteres necesario a tratar para producir algún daño (NNT). Todo el procesamiento y análisis de los datos se efectuó en los programas estadísticos SPSS 12,0 y Minitab ${ }^{\circledR}$ 15.1.0.0, para Windows.

\section{RESULTADOS}

Se encontró que la media del peso corporal en el grupo A fue $20,5 \mathrm{~g}(\sigma=2,93)$, en el grupo B 20,6 g $(\sigma=2,53)$ y en C $11,3 \mathrm{~g}(\sigma=1,52)$. Los máximos valores del peso corporal se localizaron en los grupos A y B (24,3 y 24,1 g, respectivamente), siendo estos valores considerablemente mayores que el peso máximo del grupo C $(14,1 \mathrm{~g})$. Por otro lado, los valores más bajos del peso corporal de los grupos A y B (15,5 y 14,9 g, respectivamente), también fueron mayores en comparación con los valores del grupo $\mathrm{C}$, inclusive más que el mayor valor de este último. El valor mínimo del peso corporal del grupo $\mathrm{C}$ fue $8,9 \mathrm{~g}$, muy inferior al resto de los obtenidos. En el análisis de varianza (Anova), se encontró que la diferencia entre las medias y varianzas de los grupos de estudio fue significativa $(\mathrm{F}[5,12]=74,63, p<0,000)$. Para los grupos A y B se observó valores similares, sin diferencia significativa estadísticamente (t $[2,467]$ $=-0,09, p=0,932)$; pero, ambos difirieron de manera significativa del grupo $\mathrm{C}(\mathrm{t}[2,467]=10,84$, $p<0,000$ ) (Figura 1).

La media del peso cerebral en el grupo A fue $0,96 \mathrm{~g}(\sigma=0,077)$, en el grupo B $0,97 \mathrm{~g}(\sigma=0,086)$ y en el C $0,76 \mathrm{~g}(\sigma=0,082)$. Los valores máximos del peso encefálico fueron: grupo A $1,07 \mathrm{~g}$, grupo B $1,11 \mathrm{~g}$ y grupo $\mathrm{C} 0,83 \mathrm{~g}$; los valores mínimos fueron: grupo A $0,84 \mathrm{~g}$, grupo $\mathrm{B} 0,85 \mathrm{~g}$ y grupo $\mathrm{C} 0,53 \mathrm{~g}$. Al igual que con el peso corporal, se encontró que la diferencia entre las medias y varianzas de los grupos de estudio fue significativa $(\mathrm{F}[5,12]=33,24, p<0,000)$. Para los grupos $\mathrm{A}$ y $\mathrm{B}$, se observó valores similares, sin diferencia significativa estadísticamente $(\mathrm{t}[2,467]=-0,25$, $p=0,804)$; pero, ambos difirieron de manera significativa del grupo $\mathrm{C}(\mathrm{t}[2,467]=7,14, p<0,000)$ (Figura 2). 


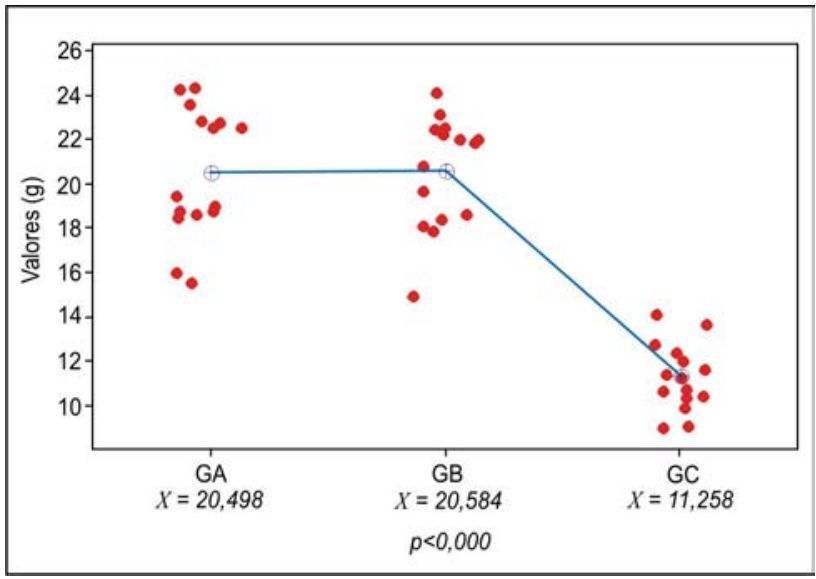

Figura 1. Comparación de los valores del peso corporal por grupos de estudio.

La media de la talla en el grupo A fue 8,71 $\mathrm{cm}(\sigma=0,61)$, en el B $8,69 \mathrm{~cm}(\sigma=0,54)$ y en el C $7,50 \mathrm{~cm}(\sigma=0,54)$. Con respecto a la talla, se encontró que los valores de los grupos A y B eran semejantes, no encontrándose diferencias significativas entre ellos $(\mathrm{t}[2,467]=0,06, p=0,950)$. Sí hubo diferencias con el grupo $\mathrm{C}$, el cual presentó los valores más bajos para la talla, situándose dichos valores por debajo del promedio obtenido en los primeros grupos $(\mathrm{t}[2,467]=5,77, p<0,000)$ (Figura 3).

En el estudio histopatológico del hipocampo (regiones CA1, CA3 y DG), se observó que existió diferencia significativa respecto a la homogeneidad; es decir, que los grupos de estudio presentaron diferencias con respecto a las variables histopatológicas, entre ellas, disminución de la densidad neuronal, necrosis neuronal, desmielinización axonal y gliosis $\left(X^{2}[9,21]=36,600, X^{2}[9,21]\right.$ $=22,200, X^{2}[9,21]=17,206$ y $X^{2}[9,21]=$ 25,797, respectivamente; $p<0,000$ ) (Figura 4). En algunas muestras histológicas del grupo $\mathrm{C}$, se observó tumefacción neuronal, la cual resultó no ser significativa. El análisis descriptivo de los valores obtenidos estableció una menor incidencia de alteraciones en los grupos A y B, en comparación con el C, como se observa al calcular el riesgo relativo (RR) para todas las variables histopatológicas; en este nivel, existió $14,12,6$ y 6,5 veces más riesgo de presentar densidad neuronal dismi-

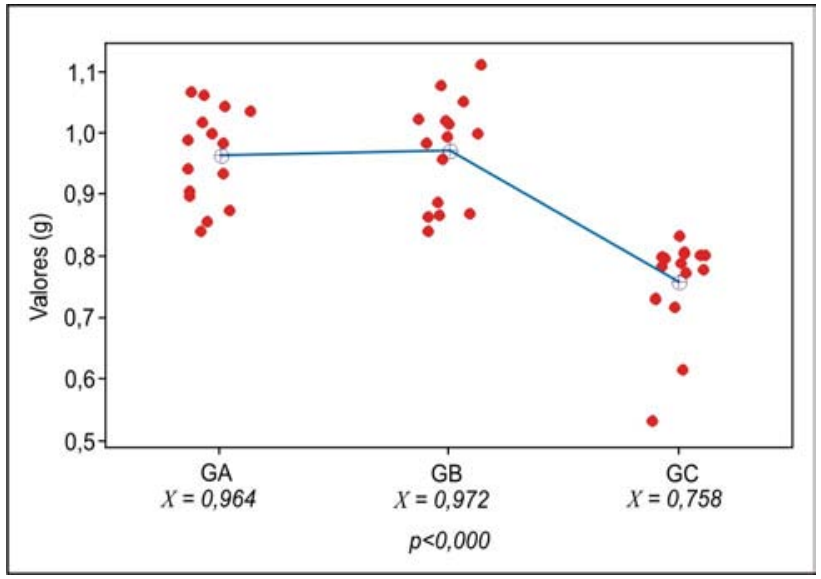

Figura 2. Comparación de los valores del peso encefálico por grupos de estudio.

nuida, necrosis neuronal, desmielinización axonal y gliosis, respectivamente, sí existía antecedente de exposición a timerosal, de acuerdo al esquema de administración utilizado.

En la corteza cerebral, se encontró diferencia significativa con respecto a la hipótesis de homogeneidad entre los grupos de estudio; además, se evidenció la presencia de densidad neuronal disminuida, necrosis neuronal, desmielinización axonal y gliosis $\left(X^{2}[9,21]=22,200, X^{2}[9,21]=26,250, X^{2}\right.$ $[9,21]=24,231, X^{2}[9,21]=16,200, p<0,000$, respectivamente) (Figura 5). El cálculo del RR para las alteraciones corticales reveló $12,7,5,7$ y 5,5

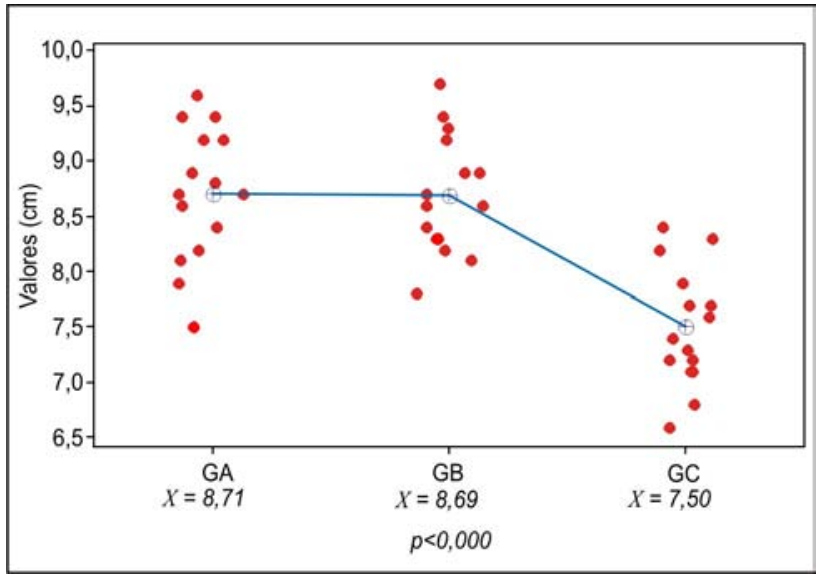

Figura 3. Comparación de los valores de la talla por grupos de estudio. 

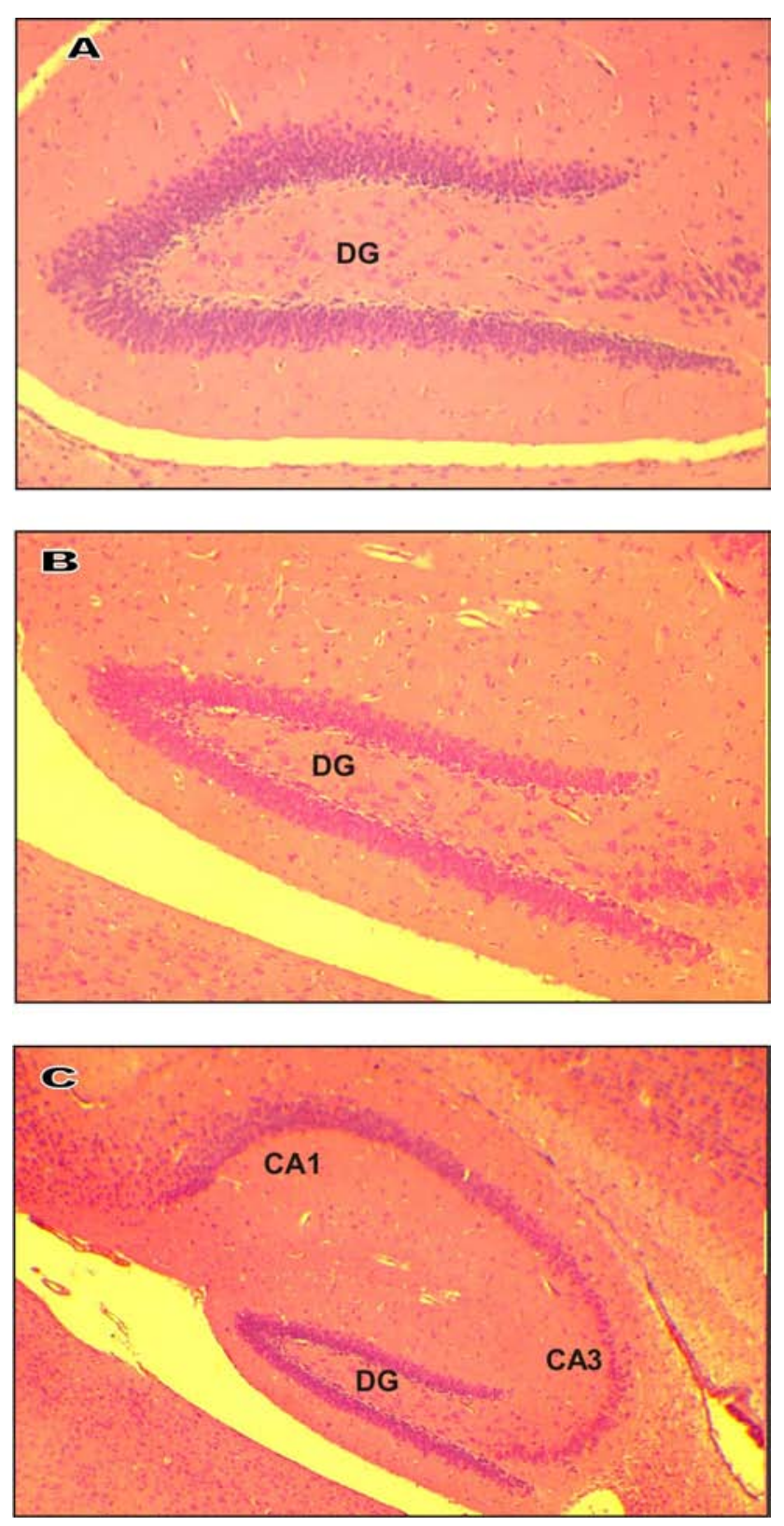

Figura 4. Hipocampo: A. Región del Gyrus dentado (DG)

(H-E x100); B. Densidad neuronal disminuida en DG

(H-E x100); C. Densidad neuronal disminuida en CA3 y DG (H-E x50).

veces más riesgo de presentar densidad neuronal disminuida, necrosis neuronal, desmielinización axonal y gliosis, respectivamente, si existía antecedente de exposición previa a timerosal, de acuerdo al esquema de administración empleado.
A nivel del cerebelo (capa molecular, células de Purkinje y células granulosas), se evidenció que existió diferencia significativa, que probó la hipótesis de que los grupos de estudio difirieron respecto a las alteraciones histopatológicas. Se especificó disminución, desmielinización axonal y necrosis de las células de Purkinje y las células granulosas, además de gliosis en todas las capas $\left(X^{2}[9,21]=\right.$ $16,200, X^{2}[9,21]=33,362, X^{2}[9,21]=10,556$, $X^{2}[9,21]=24,231$, respectivamente, $\left.p<0,000\right)$ (Figura 6). El RR para las alteraciones a nivel del cerebelo reveló que en el grupo $\mathrm{C}$ existió 5,5, 7 y 3,6 veces más riesgo de presentar disminución, desmielinización axonal y necrosis de las células de Purkinje y células granulosas, respectivamente; además, el riesgo de presentar gliosis fue 7 veces mayor en este grupo.

En general, a nivel encefálico, no se observó la presencia de teratogenicidad (anencefalia, microcefalia, etc.) y/o defectos congénitos, en los grupos de experimentación.

\section{DISCUSIÓN}

Al comparar los resultados de la media del peso corporal, el peso encefálico y la talla entre los grupos A y B, se observó valores similares que justificaron la hipótesis de que ambos grupos no presentaron diferencias significativas con respecto al grado de su desarrollo, a pesar de que se les administró sustancias diferentes, las cuales por su naturaleza inocua solo cumplieron la función de control, con respecto al grupo C. Contrariamente, el grupo C presentó los menores valores de estos parámetros, sustentando de esta manera la hipótesis de un menor desarrollo y retardo del crecimiento en este grupo; sin embargo, debemos recordar que, inicialmente, el peso corporal y la talla fueron estandarizadas como criterio de selección en el estudio (peso y talla al $7^{\circ}$ día de vida de $8,5 \pm 0,5 \mathrm{~g} \mathrm{y} 4,5 \pm 0,5 \mathrm{~cm}$, respectivamente). Concluimos, por lo tanto, que el estímulo causante del retardo en el desarrollo y el crecimiento de los hámsteres del grupo $\mathrm{C}$ fue posterior a la primera semana de su nacimiento y, en el caso del experimento, se atribuye a los efectos del timerosal en el organismo animal, dado que el 

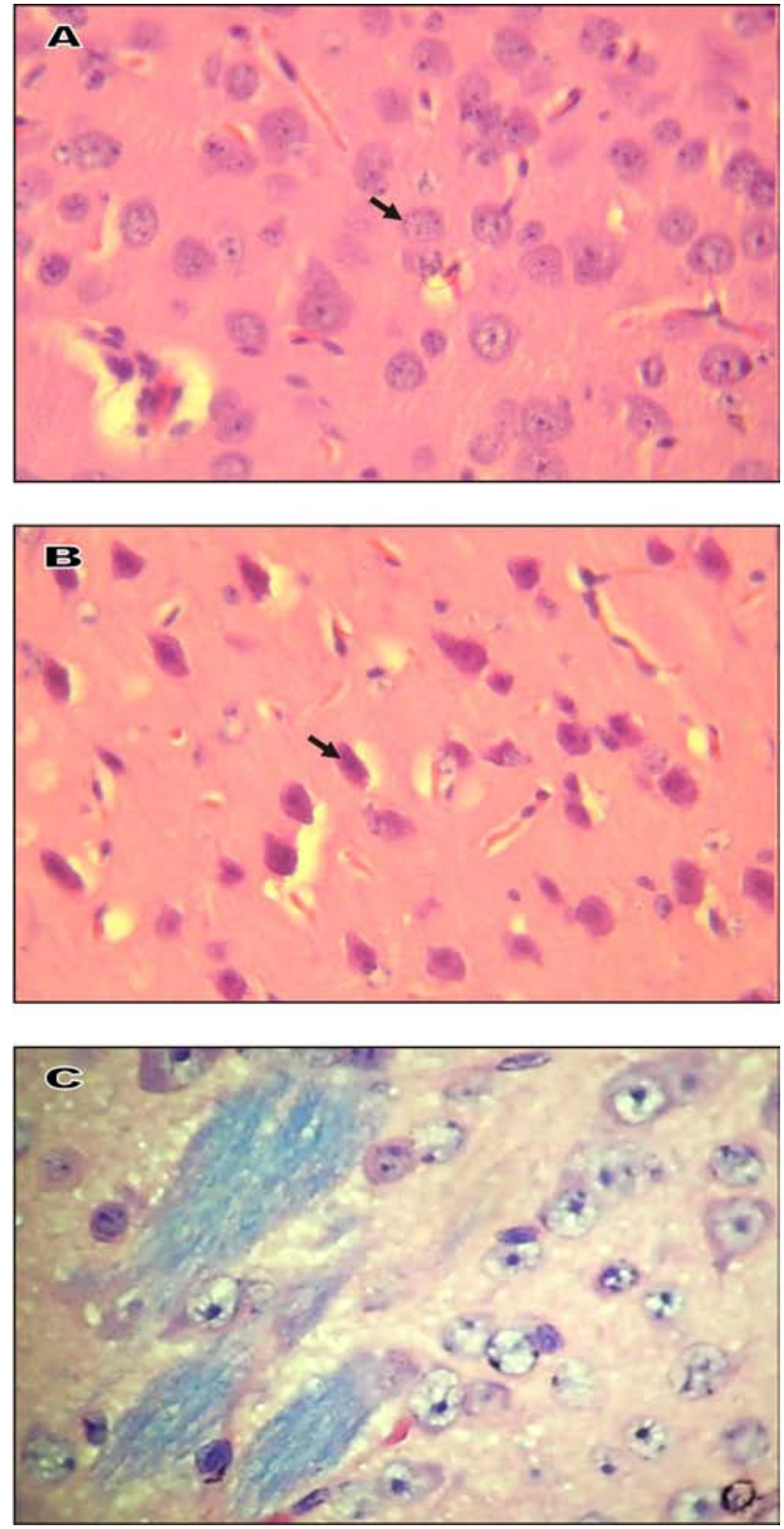

Figura 5. Corteza cerebral: A. Neuronas piramidales. (H-E. x400); B. Necrosis neuronal. (H-E. x400); C. Desmielinización axonal (luxol fast blue. x400).

resto de variables (alimentación, condiciones de cautiverio y estímulos externos) fueron idénticas en los tres grupos estudiados. Aunque no se pueda detallar los mecanismos exactos, el alto grado de significancia de las pruebas estadísticas apoya esta hipótesis.
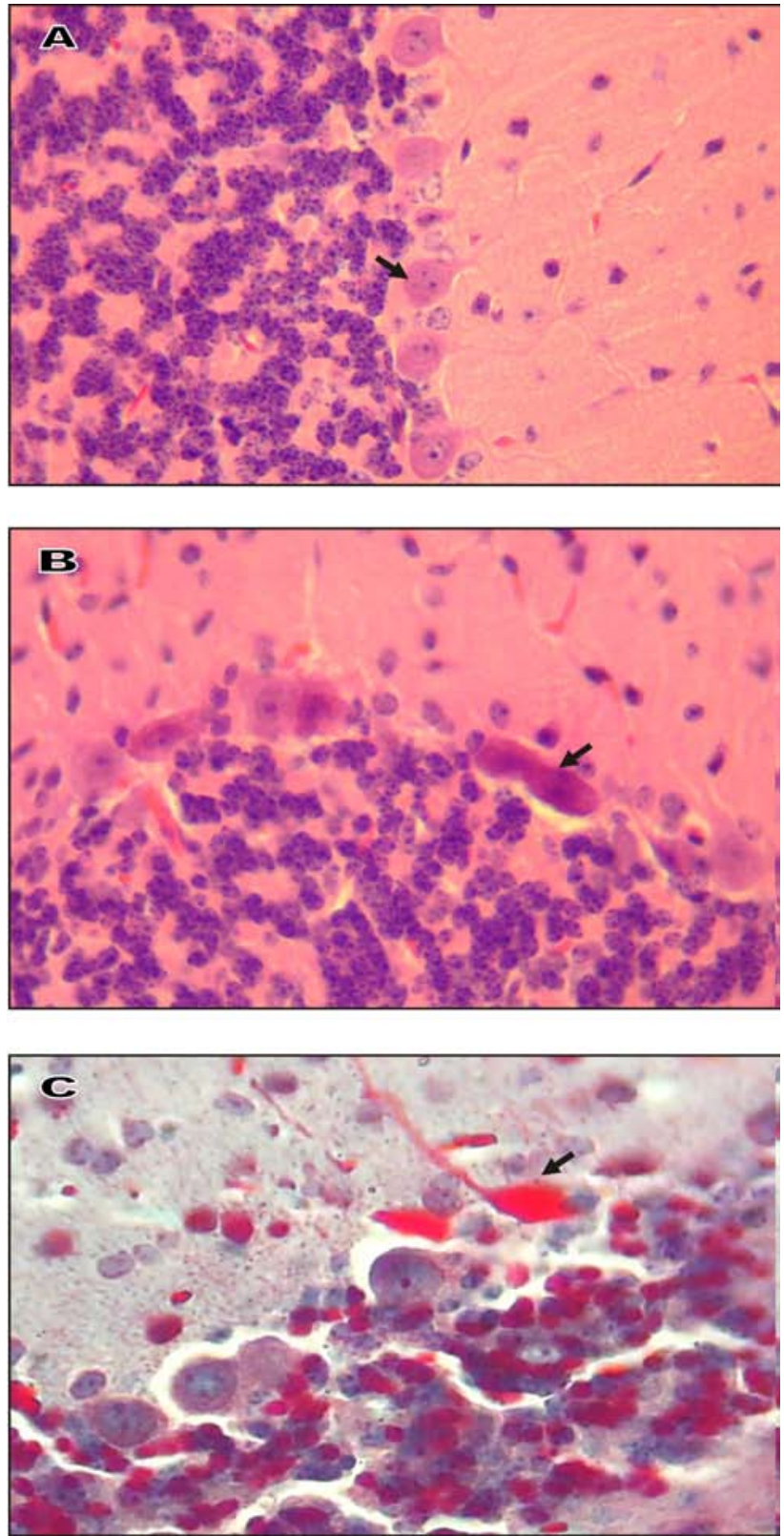

Figura 6. Cerebelo: A. Células de Purkinje (H-E x400);

B. Necrosis de las células de Purkinje. (H-E x400); C. Necrosis de las células de Purkinje (tricrómica de Gomori x400).

Otros estudios han mostrado resultados similares a los nuestros. Hornig y col. $\left({ }^{51}\right)$, utilizando cepas de ratones especialmente vulnerables a trastornos inmunológicos, cuyos cerebros se encontraban en desarrollo, y exponiéndolos a vacunas con timerosal (a dosis equivalentes al peso y la edad de los calen- 
darios de inmunización humanos iguales a los usados por nosotros), pudieron evidenciar la presencia de diversas patologías, tales como retardo del crecimiento, disminución de la locomoción, respuestas inapropiadas ante nuevos estímulos, anormalidades significativas en la arquitectura de áreas cerebrales relacionadas a la emoción y la cognición, y trastornos en las células del hipocampo, con alteraciones en los transportadores y receptores de glutamato intracerebrales. Burbacher y col. $\left({ }^{52}\right)$ llevaron a cabo un estudio comparativo de la distribución sistémica y cerebral de mercurio $(\mathrm{Hg})$ total y $\mathrm{Hg}$ inorgánico, luego de la administración intramuscular de timerosal (a dosis de vacuna y en la misma cronología de las inmunizaciones humanas) y de metilmercurio (metilHg), por vía oral, en monos infantes. Documentaron que, luego de las inyecciones de timerosal, los niveles picos sanguíneos de $\mathrm{Hg}$ se elevaron significativamente, coincidiendo con los resultados encontrados en neonatos humanos por Stajich y col. ( ${ }^{53}$ ); asimismo, hallaron que el tiempo de vida media sanguínea era aproximadamente 8,6 días, similar al informado por Pichichero y col. en niños posvacunados $\left({ }^{54}\right)$. No obstante, el cociente cerebro/sangre de $\mathrm{Hg}$ total y el porcentaje de $\mathrm{Hg}$ inorgánico intracerebral fueron mayores en el grupo que recibió timerosal, concluyendo que los niveles sanguíneos de $\mathrm{Hg}$ no son un buen indicador del riesgo de efectos adversos neurológicos ocasionados por el preservante, pues a pesar de que no se acumula en la sangre, los depósitos de $\mathrm{Hg}$ en el cerebro de los niños sí podría ocurrir, de modo que los datos sobre la seguridad del timerosal, basados únicamente en su depuración sanguínea, no son válidos $\left({ }^{52}\right)$. Qvarnstrom y col. cuantificaron también la distribución corporal de metilHg, etilHg y $\mathrm{Hg}$ inorgánico, luego de su administración por vía oral a murinos, determinando que el etilHg del timerosal ingresa rápidamente a los órganos animales (riñones, hígado, nódulos linfáticos), de manera creciente durante los periodos de exposición, para luego ser degradado a $\mathrm{Hg}$ inorgánico $\left({ }^{55}\right)$. Asimismo, cuando se estudió comparativamente la distribución de etil $\mathrm{Hg}$ y de $\mathrm{Hg}$ inorgánico, aplicados por vía parenteral (imitando la dosis por peso y la cronología de las vacunaciones humanas, tal como en el presente trabajo), los resultados mostraron que los niveles de $\mathrm{Hg}$ fueron más altos en el hígado y en los riñones de los animales ex- puestos a $\mathrm{Hg}$ inorgánico; mientras que, en el grupo de animales expuestos a etil $\mathrm{Hg}$, las concentraciones de $\mathrm{Hg}$ fueron mayores en la sangre y en el cerebro ${ }^{(56)}$. De otro lado, Harry y col. han concluido que la distribución de $\mathrm{Hg}$ en los tejidos corporales, luego de su administración por vía intramuscular, no es comparable a los resultados obtenidos luego de la exposición oral y que, adicionalmente, el metilHg no parece ser un buen modelo de comparación con los compuestos conteniendo etilHg $\left({ }^{57}\right)$. Zareba y col., en un estudio por publicarse en la revista $J$ Appl Toxicol, han reportado hallazgos similares en ratones recién nacidos, señalando que, luego de su administración intramuscular al $10^{\circ}$ día posnatal, el etilHg mostró significativas diferencias farmacocinéticas en su metabolismo y distribución tisular en relación al metilHg: mayor proporción de $\mathrm{Hg}$ inorgánico a nivel cerebral, de $\mathrm{Hg}$ orgánico a nivel renal y mayores concentraciones de ambas formas mercuriales a nivel hepático, en comparación con una dosis de exposición equivalente de metilHg.

Diversos otros autores han comunicado cantidades apreciables de timerosal en la sangre y el sistema nervioso central de los animales en los que el preservante ha sido probado, estableciéndose su pasaje a través de la barrera placentaria y hematoencefálica $\left({ }^{58,59}\right)$. Estudios en roedores han mostrado que esta sustancia es altamente inestable, disociándose en el organismo en etilHg y tiosalicilato; el etilHg, es capaz de atravesar las membranas celulares y, luego, intracelularmente, ser convertido en $\mathrm{Hg}$ inorgánico, la forma mercurial más tóxica, acumulándose preferentemente en los riñones y en el cerebro $\left({ }^{60}\right)$. Gasett y col. observaron una mayor tasa de muertes fetales cuando el timerosal se aplicaba tópicamente sobre ratas preñadas $\left({ }^{58}\right)$. Itoi y col. también encontraron propiedades abortivas cuando esta sustancia se aplicó sobre la conjuntiva de conejas embarazadas; adicionalmente, estos autores informaron sobre la aparición de malformaciones congénitas solo en el grupo de animales expuestos a timerosal $\left({ }^{61}\right)$. Digar y col. documentaron tasas de mortalidad cuatro veces mayores luego de la aplicación de timerosal en el saco vitelino de huevos de pollo $\left({ }^{62}\right)$. Batts y col. observaron disminución de la fertilidad en ovejas, pues comprobaron que el timerosal producía toxicidad sobre la función ciliar 
$\left.{ }^{63}\right)$. Goncharuk y col. mostraron también menor fertilidad y mayor letalidad en ratas expuestas a compuestos inhalados de etilHg $\left({ }^{64}\right)$. Kahn y col. observaron atrofia ovárica y menor sobrevivencia en ratones expuestos a $\mathrm{Hg}$ inorgánico $\left({ }^{65}\right)$. Goth y col. recientemente han informado que el timerosal es altamente tóxico sobre el sistema inmunológico, pues altera las propiedades o causa la muerte de las células dendríticas de ratones in vitro, a dosis nanomolares. Es conveniente señalar que, estas células actúan como presentadoras de antígenos y estimulan la inmunidad merced a la activación de los linfocitos T ( ${ }^{66}$ ). Últimamente, estudios similares han hallado que el timerosal inhibe la secreción de diversas citoquinas inflamatorias (factor de necrosis tumoral (TNF) alfa, interleuquina (IL) 6 e IL 12p70) sobre células dendríticas humanas, induciendo el incremento de la inmunidad humoral (TH2) e inhibiendo la inmunidad mediada por células (TH1). Tales efectos fueron mediados por la depleción intracelular de glutatión sobre las células dendríticas, observándose la corrección de los mismos con la aplicación exógena de dicha sustancia ${ }^{(67)}$. Ueha-Ishibashi y col. evaluaron in vitro las acciones citotóxicas del timerosal sobre linfocitos tímicos de ratas, observando que concentraciones micromolares (3 a $30 \mu \mathrm{M}$ ) del preservante despolarizaban las membranas celulares, incrementando los niveles de calcio intracelular; de manera dosisdependiente, el timerosal ocasionó también pérdida de la integridad de las membranas, daño oxidativo y la apoptosis de las células estudiadas $\left({ }^{68}\right)$.
Nuestra investigación mostró diferencias muy significativas, en relación a la mayor incidencia de daños histopatológicos severos a nivel encefálico en el grupo de animales expuestos a timerosal, en todas las herramientas estadísticas empleadas, en comparación con los grupos control. El patrón anterior se observó para todas las variables histopatológicas evaluadas (disminución de la densidad neuronal, necrosis neuronal, desmielinización axonal y gliosis) y en todas las zonas cerebrales estudiadas (hipocampo, corteza cerebral y cerebelo), según se muestra en la Tabla 2 .

Estos hallazgos son concordantes con los estudios recientes sobre el metabolismo del timerosal. Esta sustancia es un preservante empleado en algunas vacunas y agentes biológicos, a concentraciones desde 0,003 hasta $0,01 \%$. Contiene $49,6 \%$ de $\mathrm{Hg}$ por peso. En soluciones salinas, se disocia en cloruro de etilHg y ácido tiosalicílico $\left({ }^{69}\right)$; una vez disociado, el etilHg tiene una altísima afinidad por los radicales sulfhidrilos $(\mathrm{SH})$ que se encuentran en algunas enzimas antioxidantes, como el glutatión o las metalotioneínas (proteínas producidas por el hígado), enzimas que tienen un límite de unión al metal pesado (saturación), dejando libre al etilHg excedente $\left({ }^{70-72}\right)$. Esto permite aseverar que, una exposición elevada a timerosal, sobrepasaría los límites de saturación por parte de los antioxidantes naturales. Como consecuencia, el etilHg en exceso se uniría a los grupos $\mathrm{SH}$ de otras importantes proteínas estructurales y/o funcionales.

Tabla 2. Comparación de los resultados de las variables estadísticas entre los grupos B y C.

\begin{tabular}{|c|c|c|c|c|c|c|c|c|c|}
\hline \multirow[b]{3}{*}{ Variables } & \multicolumn{9}{|c|}{ Región de estudio } \\
\hline & \multicolumn{3}{|c|}{ Hipocampo } & \multicolumn{3}{|c|}{ Corteza cerebral } & \multicolumn{3}{|c|}{ Cerebelo } \\
\hline & $\mathrm{RR}$ & RRA(\%) & NNT & $\mathrm{RR}$ & RRA(\%) & NNT & $\mathrm{RR}$ & RRA(\%) & NNT \\
\hline Densidad neuronal disminuida & 14 & 87 & 1,15 & 12 & 73 & 1,36 & 5,5 & 60 & 1,67 \\
\hline Necrosis neuronal & 12 & 73 & 1,36 & 7,5 & 87 & 1,15 & 7 & 80 & 1,25 \\
\hline Desmielinización axonal & 6 & 67 & 1,50 & 7 & 80 & 1,25 & 3,67 & 53 & 1,88 \\
\hline Gliosis & 6,5 & 75 & 1,36 & 5,5 & 60 & 1,67 & 7 & 80 & 1,25 \\
\hline
\end{tabular}

RRA: Reducción del riesgo absoluto (diferencia de riesgos).

RR: Riesgo relativo.

NNT: Número de hámsteres necesario a tratar para producir algún daño. 
De otro lado, recientemente se ha descrito la importancia de los canales de calcio intracitoplasmáticos de neuronas, células cerebelosas y células endoteliales capilares cerebrales (las mismas que conforman la barrera hemato-encefálica) de ratones, en el proceso de diferenciación neuronal y progresión de la neurogénesis $\left({ }^{73,74}\right)$. Precisamente, la activación de dichos canales está mediada por la oxidación coordinada de radicales $\mathrm{SH}$, sobre los cuales el timerosal ejerce un potente efecto modulador, incrementando las concentraciones de calcio intracitoplasmático; de esta manera, se ha señalado que este último puede alterar la fisiología de las células nerviosas, gracias a sus efectos sobre el estado de óxido-reducción, conduciendo a trastornos funcionales, depleción de glutatión y aumento del estrés oxidativo $\left({ }^{75-79}\right)$.

Asimismo, la alta liposolubilidad exhibida por el timerosal le permite atravesar fácilmente la barrera hematoencefálica, generando daños irreversibles sobre las células nerviosas. Por ejemplo, se ha encontrado también que el $\mathrm{Hg}$ puede alterar el número y la división de las células; de esta manera, puede afectar el desarrollo neuronal, ocasionando alteraciones en la proliferación celular y efectos locales neuropatológicos, que han sido vinculados con déficits específicos de la conducta $\left(^{80}\right)$.

Numerosos estudios biomoleculares describen la capacidad del timerosal para ocasionar desórdenes neurológicos que lo vinculan como el agente causal de diversas enfermedades del neurodesarrollo infantil $\left({ }^{81}\right)$. Haley y col. $\left({ }^{70}\right)$ han demostrado la neurotoxicidad del timerosal, debido al enorme poder de penetración que posee en tejidos grasos, tales como el sistema nervioso central, documentando necrosis de neuronas humanas in vitro, luego de exponerlas a soluciones nanomolares de timerosal. Otros estudios sobre células nerviosas humanas han demostrado también que, concentraciones nanomolares a micromolares de timerosal son capaces de inducir muerte neuronal, neurodegeneración, daño a las membranas celulares y alteraciones sobre el ADN, en pocas horas de exposición $\left({ }^{71,72,82-84}\right)$. Últimamente, se ha mostrado que, pequeñísimas cantidades de timerosal son igualmente capaces de interrumpir críticamente las vías de comunicación interneuronales y los eventos bioquímicos necesarios para el adecuado desarrollo neurológico en el ser humano $\left.{ }^{(85,86}\right)$. Asimismo, se ha documentado que el timerosal es tóxico sobre los neurotúbulos, interfiere sobre enzimas antioxidantes cerebrales, daña las enzimas de reparación del ADN, interfiere con la producción mitocondrial de energía, bloquea las proteínas recaptadoras de glutamato cerebrales, tiene la capacidad de unirse al ADN neuronal y puede perturbar las funciones de las membranas celulares nerviosas $\left({ }^{87-89}\right)$. Leong y col. demostraron que, la exposición a concentraciones nanomolares de $\mathrm{Hg}$, alteró las estructuras de las membranas neuronales y las líneas de crecimiento celulares $\left({ }^{90}\right)$; tales hallazgos han sido replicados cuando se ha empleado timerosal $\left({ }^{91-93}\right)$. James y col. $\left({ }^{72}\right)$ han mostrado que el timerosal induce estrés oxidativo y la apoptosis de neuronas, astrocitos y células $\mathrm{T}$ humanas, activando vías metabólicas mitocondriales de muerte celular. Lo anterior explica las alteraciones observadas a nivel de la estructura neuronal, que traería como consecuencia una disminución en la población de neuronas, lo cual se asocia en la clínica a trastornos en el desarrollo psicomotor, retardo del lenguaje, problemas de comportamiento, pérdida de la visión, audición, convulsiones, autismo, etc $\left({ }^{94-96}\right)$. Recientemente, diversas investigaciones han demostrado también que el timerosal es capaz de dañar severamente la metilación, una ruta metabólica crítica en la habilidad de los factores de crecimiento para promover el desarrollo neurológico normal $\left({ }^{72,97-99}\right)$. Precisamente, se ha encontrado que la exposición a metales pesados, tales como $\mathrm{Hg}$, plomo y aluminio, pueden causar enfermedades del neurodesarrollo en los seres humanos, gracias a que son capaces de interferir con la metilación y disminuir diversos factores del desarrollo, tales como el factor de crecimiento neurotrópico, el factor de crecimiento similar a la insulina tipo 1 y el factor neurotrópico cerebral, todos los cuales son indispensables para el buen desarrollo y la sobrevivencia del sistema nervioso $\left({ }^{100,101}\right)$.

El timerosal también ha sido asociado a profundos efectos sobre el sistema inmunológico. Havarinasab y col. han estudiado los trastornos inmunológicos luego de la administración oral de compuestos mercuriales orgánicos e inorgánicos sobre ratones de experimentación. Dichos autores han descrito que, si bien todos los agentes mercuriales tienen efectos 
inmunosupresores, tanto el metilHg como el etilHg muestran mayor capacidad inmunodepresiva, en comparación con el Hg inorgánico. Sin embargo, en cepas de ratones susceptibles, la administración de $\mathrm{Hg}$ produce un estado de inmunosupresión transitoria, de 1 a 3 semanas de duración, seguido de una segunda fase de inmunoestimulación dependiente de la activación policlonal de linfocitos $\mathrm{B}$, en la que aparecen anticuerpos antinucleolares, anticuerpos antifibrilares nucleares, depósito de complejos autoinmunes a nivel sistémico, glomerulonefritis, incremento de los niveles séricos de inmunoglobulina (Ig) E, IgG 1, IgG 2a, IL 2, IL 4, IL 15 e interferón-gamma, hipergammaglobulinemia y esplenomegalia, condición denominada 'síndrome de autoinmunidad inducido por mercurio' (102-106). Dichos autores han informado que, a dosis equimolares, el metilHg tiene el menor efecto inmunoestimulante, autoinmunogénico y generador de complejos autoinmunes; mientras que el etilHg tiene efectos comparables a los del $\mathrm{Hg}$ inorgánico, siendo responsable de graves daños mediados por mecanismos autoinmunes y una alta mortalidad $\left({ }^{102}\right)$.

Si bien, la dosis dañina de timerosal en los seres humanos (en particular sobre los recién nacidos y niños pequeños) aún no ha sido formalmente esclarecida, se sabe que el derivado mercurial que éste contiene (etilHg), al cual se le atribuye sus efectos nocivos, puede producir neurotoxicidad, tal como lo demuestran las múltiples investigaciones antes señaladas. Debido a que, aún a la fecha, no se cuenta con datos definitivos que comparen la toxicidad del etilHg con la del metilHg, otro agente mercurial de reconocida toxicidad neurológica, estudiado ampliamente a lo largo de décadas, la FDA considera a ambos como equivalentes en la evaluación del riesgo, por lo que ha agrupado a estos dos compuestos bajo la denominación de 'mercuriales orgánicos', determinando que su dosis de exposición máxima permisible es 0,43 microgramos por kilogramo de peso diarios $(\mu \mathrm{g} / \mathrm{kg} / \mathrm{día})$ $\left({ }^{107}\right)$. Se ha señalado que, la toxicidad ocasionada por los mercuriales orgánicos depende del tipo específico de compuesto, la vía de entrada, la dosis, el tiempo y la edad de exposición $\left({ }^{47,108}\right)$.

Los efectos más relevantes de la exposición al etilHg del timerosal se asocian a la mayor vulne- rabilidad del cerebro fetal e infantil, puesto que la exposición crónica a $\mathrm{Hg}$ orgánico es especialmente tóxica para un sistema nervioso inmaduro, produciendo alteraciones en su desarrollo estructural (necrosis focal de las neuronas corticales y cerebelosas, desmielinización axonal, etc.), y funcional (interferencia en el proceso de migración de las capas neuronales corticales y subcorticales) $\left({ }^{109-112}\right)$, los cuales fueron corroborados en nuestro estudio.

Es de resaltar que, una de las anormalidades neurológicas más consistentes encontradas en los estudios post-mórtem y en los estudios por imágenes de los cerebros de las personas con autismo, es una marcada pérdida de las células de Purkinje y atrofia a nivel cerebeloso (113-116). Numerosos estudios en animales han mostrado que estas células son especialmente vulnerables a muy diversos insultos, entre los que destaca la exposición a metales pesados (Hg, plomo, arsénico, cadmio y bismuto) $\left.{ }^{(117-123}\right)$, dañando sus receptores recaptadores de glutamato. La excesiva estimulación neuronal asociada a niveles elevados de glutamato intracerebrales aumenta la producción de especies reactivas de oxígeno, lo que a su vez induce estrés oxidativo, citotoxicidad y daño neuronal $\left({ }^{124,125}\right)$, razón por la que se ha postulado que, la exposición a metales pesados en fases muy tempranas de la vida, puede iniciar toda esta cadena de eventos que conducen, finalmente, a la muerte neuronal $\left({ }^{126}\right)$. Es conveniente señalar que, el más reciente y ambicioso estudio genético de los DEA no encontró evidencias que respaldaran la hipótesis de que estas enfermedades fueran hereditarias, pero halló cierta vinculación con los genes relacionados a las neurexinas, las cuales precisamente son las responsables de la sinaptogénesis mediada por glutamato $\left({ }^{127}\right)$. Asimismo, otros estudios recientes han mostrado evidencias de gliosis asociada a la pérdida de células de Purkinje y un marcado proceso neuroinflamatorio difuso cerebral en niños con autismo $\left({ }^{128-131}\right)$. Precisamente, la persistencia de $\mathrm{Hg}$ inorgánico en el cerebro de los animales de experimentación, luego de haber sido expuestos a metilHg, timerosal o $\mathrm{Hg}$ inorgánico, ha sido asociada a un incremento significativo de las células de la microglía, disminución del número de astrocitos y afectación de las células de Purkinje $\left({ }^{52,132-134}\right)$. Finalmente, diversos estudios neuropatológicos han mostrado anormalidades en la organización de la 
citoarquitectura de la corteza cerebral y estructuras subcorticales en pacientes con autismo, sugiriéndose que dichos defectos en la maduración neuronal y en la organización cortical pueden ser los responsables de los problemas neurológicos vistos en esta enfermedad $\left({ }^{128,135-137}\right)$.

Todas estas evidencias han conducido a recientes trabajos de revisión, que han asociado los hallazgos histopatológicos a nivel encefálico, el estrés oxidativo, la peroxidación lipídica y la deficiencia de glutatión, vistos en el autismo y otras enfermedades del neurodesarrollo infantil, con la exposición a metales pesados, concluyéndose que la acumulación de estos últimos puede ocurrir en los niños cuya capacidad de desintoxicación sea limitada o se encuentre comprometida. Los metales pesados pueden entonces alcanzar niveles críticos que conduzcan a estrés oxidativo, descompensación y daño neurológico, resultando en disminución de las células nerviosas y la pérdida de las habilidades del desarrollo previamente adquiridas $\left({ }^{81,138-142}\right)$.

En conclusión, la exposición a timerosal, en cantidades equivalentes al contenido en las vacunas humanas, disminuyó de manera significativa el peso corporal, el peso encefálico y la talla de hámsteres posnatales; de esta manera, les produjo un menor desarrollo y retardo en el crecimiento. Asimismo, produjo severos efectos neurotóxicos a nivel encefálico, constatándose alteraciones histopatológicas a nivel del hipocampo, la corteza cerebral y el cerebelo. Se recuerda que estas conclusiones solo se aplican sobre el esquema de administración antes detallado (dosis, concentración, dilución, vía e intervalo de aplicación). Entre las alteraciones histopatológicas encontradas a nivel del hipocampo (regiones CA1, CA3 y DG), la corteza cerebral (lóbulos occipital, parietal y frontal) y el cerebelo (células de Purkinje y células granulosas), se distinguió disminución de la densidad neuronal, necrosis neuronal, desmielinización axonal y gliosis. Además, el riesgo de presentar alguna de estas alteraciones fue muy elevado solo en el grupo de hámsteres posnatales expuestos a timerosal.

Dados los amplios vacíos en el conocimiento de las características farmacocinéticas y farmacodinámicas del timerosal, así como de sus propiedades tóxicas sobre el sistema nervioso e inmunológico, se requiere a la brevedad más estudios de características cuantitativas en modelos animales. No obstante, si bien es cierto, es muy difícil extrapolar estos hallazgos a otros grupos de experimentación animal y sobre los seres humanos, nuestros resultados, así como las múltiples evidencias científicas recientemente publicadas sobre el timerosal, indican claramente la naturaleza neurotóxica de esta sustancia, a las mismas dosis y en la misma cronología de las inmunizaciones humanas, por lo que sugerimos el empleo de preservantes alternativos en las vacunaciones; en especial, aquellas dirigidas a gestantes, neonatos y niños pequeños, basados en los principios de prevención y precaución de todas las intervenciones médicas.

\section{AGRADECIMIENTOS}

Al Dr. José Ernesto Ráez González, Jefe del Departamento Académico de Patología, Facultad de Medicina de San Fernando, UNMSM.

Al Dr. Juan Manuel Rodríguez-Tafur Dávila, profesor del Departamento Académico de Ciencias Dinámicas, Sección de Farmacología, Facultad de Medicina de San Fernando, UNMSM.

\section{REFERENCIAS BIBLIOGRÁFICAS}

1. World Health Organization. Vaccines and Biologicals: Recommendations from the Strategic Advisory Group of Experts. Wkly Epidemiol Rec. 2002;77:305-6.

2. McGinnis W. Mercury and autistic gut disease. Environ Health Perspect. 2001;109:A303-A304.

3. Bernard S, Enayati A, Redwood L, et al. Autism: a novel form of mercury poisoning. Med Hypotheses. 2001;56:462-71.

4. Ritvo E, Freeman B, Pingree C, et al. The UCLA-University of Utah epidemiologic survey of autism: Prevalence. Am J Psychiatry. 1989;146:194-9.

5. Burd L, Fisher W, Kerbeshian J. A prevalence study of pervasive developmental disorders in North Dakota. J Am Acad Child Adolesc Psychiatry. 1997;26:700-3.

6. Bertrand J, Mars A, Boyle C, et al. Prevalence of autism in a United States population: the BrickTownship, New Jersey, investigation. Pediatrics. 2001;108:1155-61.

7. Byrd R, Sage A, Keyzer J, et al. Report to the Legislature on the principal findings from the epidemiology of autism in California: A comprehensive pilot study. M.I.N.D. Institute. University of California, Davis. October 17, 2002.

8. Yeargin-Allsopp M, Rice C, Karapurkar T et al. Prevalence of autism in a US metropolitan area. JAMA, 2003; 289: 49-55. 
9. California Department of Developmental Services: Autistic Spectrum Disorders-Changes in the California Caseload An Updated: 1999 through 2002. Sacramento, CA: State of California, 2003.

10. Gerlai R, Gerlai J. Autism: a large unmet medical need and a complex research problem. Physiol Behav. 2003;79:461-70.

11. Gurney J, Fritz M, Ness K, et al. Analysis of prevalence trends of autism spectrum disorder in Minnesota. Arch Pediatr Adolesc Med. 2003;157:622-7.

12. Blaxill M, Baskin D, Spitzer W. Commentary: Blaxill, Baskin and Spitzer on Croen et al: (2002), the changing prevalence of autism in California. J Autism Dev Disord. 2003;33:223-6.

13. Palmer R, Blanchard S, Stein Z, et al. Environmental mercury release, special education rates, and autism disorder: an ecological study in Texas. Health Place. 2006;12:203-9.

14. Blaxill M. What's going on? The question of time trends in autism. Public Health Rep. 2004;119:536-51.

15. Gerlai R, Gerlai J. Autism: A for pharmacotherapics? Drug Discov Today. 2004;9:366-74.

16. Newschaffer C, Falb M, Gurney J. National autism prevalence trends from United States special education data. Pediatrics. 2005;115:277-82.

17. Mercury in Medicine: Taking unnecessary risks. A report prepared by The Staff of the Subcommittee on Human Rights and Wellness Committee on Government Reform. United States House of Representatives. Chairman Dan Burton. May 2003.

18. Goldman L, Shannon M, and the Committee on Environmental Health. American Academy of Pediatrics. Technical Report: Mercury in the Environment: Implications for Pediatricians. Pediatrics. 2001;108:197-205.

19. Control Disease Center (CDC). Notice to readers: thimerosal in vaccines: a Joint Statement of the American Academy of Pediatrics and the Public Health Service. MMWR. 1999;48:563-5.

20. American Academy of Family Physicians. Thimerosal in vaccines. Joint statement of the AAFP, the American Academy of Pediatrics (AAP), the Advisory Committee on Immunization Practices (ACIP) and the United States Public Health Service (PHS). http://www.aafp.org/x1566.xml. Accessed Apr 30, 2006.

21. Bigham M, Copes R, Srour L. Exposure to thimerosal in vaccines used in Canadian infant immunization programs, with respect to risk of neurodevelopmental disorders. Can Commun Dis Rep. 2002;28:69-80.

22. Joint Statement of the American Academy of Pediatrics (AAP) and the US Public Health Service (PHS). Pediatrics. 1999;1049:568-9.

23. Joint Statement Concerning Removal Thimerosal from Vaccines: June 22, 2000: The American Academy of Family Physicians. The American Academy of Pediatrics. The Advisory Committee on Immunization Practices. The United States Public Health Service (PHS).

24. World Health Organization. Global Advisory Committee on Vaccine Safety, 20-21 June 2002. Wkly Epidemiol Rec. 2002;77:389-404.

25. Pless R, Risher J. Mercury, infant neurodevelopment, and vaccination. J Pediatr. 2000;136:571-3.
26. Thimerosal in vaccines - An Interim Report to Clinicians. American Academy of Pediatrics. Committee of Infectious Diseases and Committee on Environmental Health. Pediatrics, 1999;104:570-4.

27. Geier D, Geier M. Neurodevelopmental disorders after thimerosal-containing vaccines: a brief communication. Exp Biolo Med. 2003;228:660-4.

28. Geier D, Geier M. Thimerosal in childhood vaccines, neurodevelopmental disorders, and heart disease in the United States. J Am Phys Surg. 2003;8:6-11.

29. Geier D, Geier M. An assessment of the impact of thimerosal on neurodevelopmental disorders. Pediatr Rehabil. 2003;6:97102.

30. Geier D, Geier M. Neurodevelopmental disorders following thimerosal-containing childhood immunizations: a follow-up analysis. Int J Toxicol. 2004;23:369-75.

31. Geier D, Geier M. A two-phased population epidemiological study of the safety of thimerosal containing vaccines: a followup analysis. Med Sci Monit, 2005;11:CR160-CR170.

32. Geier D, Geier M. A meta-analysis epidemiological assessment of neurodevelopmental disorders following vaccines administered from 1994 through 2000 in the United States. Neuroendocrinol Lett. 2006;27:401-13.

33. Verstraeten T, Davis R, DeStefano F, et al. Safety of thimerosal-containing vaccines: a two-phased study of computerized health maintenance organization databases. Pediatrics. 2003;112:1039-48.

34. Stehr-Green P, Tull P, Stellfeld M, et al. Autism and thimerosal-containing vaccines: lack of consistent evidence for an association. Am J Prev Med. 2003;25:101-6.

35. Madsen K, Lauritsen M, Pedersen C, et al. Thimerosal and the occurrence of autism: negative ecological evidence from Danish population-based data. Pediatrics. 2003;112:604-6.

36. Hviid A, Stellfeld M, Wohlfahrt J, et al. Association between thimerosal containing vaccine and autism. JAMA. 2003;290:1763-6.

37. Andrews N, Miller E, Grant A, et al. Thimerosal exposure in infants and developmental disorders: a retrospective cohort study in the United Kingdom does not support a causal association. Pediatrics. 2004;114:584-91.

38. Heron J, Golding J, and the ALSPAC Study Team. Thimerosal exposure in infants and developmental disorders: a prospective cohort study in the United Kingdom does not support a causal association. Pediatrics. 2004;114:577-83.

39. Fombonne E, Zakarian R, Benet A, et al. Pervasive developmental disorders in Montreal, Quebec, Canada: Prevalence and links with immunizations. Pediatrics. 2006;118:139-50.

40. Kravchenko A, Dzagurov S, Chervonskaia G. Evaluation of the toxic action of prophylactic and therapeutic preparations on cell cultures. Communication III. Revealing the toxic properties of medical biological preparations from the degree of cell damage in continuous cell line L132. Zh Mikrobiol Epidemiol Immunobiol. 1983;3:87-92.

41. Cox N, Forsyth A. Thimerosal allergy and vaccination reactions. Contact Dermatitis. 1988;18:229-33.

42. Forstrom L, et al. Merthiolate hypersensitivity and vaccination. Contact Dermatitis. 1980;6:241-5. 
43. Rohyans J, et al. Mercury toxicity following merthiolate ear irrigations. J Pediatr. 1984;104:311-3.

44. Seal D, Ficker L, Wright P, et al. The case against thimerosal. Lancet. 1991;338:315-6.

45. Ministerio de Salud del Perú (MINSA). Normas de control de enfermedades prevenibles por vacunación. 1999:65-76.

46. American Academy of Pediatrics Committee on Infectious Diseases. Recommended childhood immunization scheduleUnited States, January-December 2001. Pediatrics. 2001;107:202-4.

47. Rice D, Barone S. Critical periods of vulnerability for the developing nervous system: evidence from humans and animal models. Environ Health Perspect. 2000;108:511-33.

48. Holladay S, Smialowitz R. Development of the murine and human immune system: differential effects of immunotoxicants depend on time of exposure. Environ Health Perspect. 2000;108:463-73.

49. Fink G, Zilles K, Schleicher A. Postnatal development of forebrain regions in the autoimmune NZB-mouse. A model for degeneration in neuronal systems. Anat Embryol (Berl). 1991; 183:579-88

50. The US Environmental Protection Agency. Integrated Risk Information System. Reference dose for chronic oral exposure (RfD). In: Methylmercury (MeHg) (CASRN 22967-92-6). Available at: http://www.epa.gov/iris/subst/0073.htm. Accessed Apr 22, 2006.

51. Hornig M, Chian D, Lipkin W. Neurotoxic effects of postnatal thimerosal are mouse strain dependent. Mol Psychiatry. 2004;9:833-45.

52. Burbacher T, Shen D, Liberato N, et al. Comparison of blood and brain mercury levels in infant monkeys exposed to methylmercury or vaccines containing thimerosal. Environ Health Perspect. 2005;113:1015-21.

53. Stajich G, Lopez G, Harry S, et al. Iatrogenic exposure to mercury after hepatitis $\mathrm{B}$ vaccination in preterm infants. $\mathrm{J}$ Pediatr. 2000;136:679-81.

54. Pichichero M, Cernichiari E, Lopreiato J, et al. Mercury concentrations and metabolism in infants receiving vaccines containing thiomersal: a descriptive study. Lancet. 2002;360:1737-41.

55. Qvarnstrom J, Lambertsson L, Havarinasab S, et al. Determination of methylmercury, ethylmercury, and inorganic mercury in mouse tissues, following administration of thimerosal, by species-specific isotipe dilution GC. inductively coupled plasma-MS. Anal Chem. 2003;75:4120-4.

56. Orct T, Blanusa M, Lazarus $M$, et al. Comparison of organic and inorganic mercury distribution in suckling rat. J Appl Toxicol. 2006;26:536-9.

57. Harry G, Harris M, Burka L. Mercury concentrations in brain and kidney following ethylmercury, methylmercury and Thimerosal administration to neonatal mice. Toxicol Lett. 2004;154:183-9.

58. Gassett A, Itoi M, Ishii Y, et al. Teratogenicities of ophthalmic drugs II. Teratogenicities and tissue accumulation of thimerosal. Arch Ophthalmol. 1975;93:52-5.

59. Slikker W Jr. Developmental neurotoxicology of therapeutics: survey of novel recent findings. Neurotoxicology. $2000 ; 21: 250$.
60. Magos L. Neurotoxic character of thimerosal and the allometric extrapolation of adult clearance half-time to infants. J Appl Toxicol. 2003;23:263-9.

61. Itoi M, Ishii Y, Kaneko N. Teratogenicities of antiviral opththalmics on experimental animals. Jpn J Clin Ophthal. 1972;26:631-40.

62. Digar A, Senshama G, Samal S. Lethality and teratogenicity of organic mercury (thimerosal) on the chick embryo. J Anat Soc India. 1987;36:153-6.

63. Batts A, Marriott C, Martin G. The effect of some preservatives used in nasal preparations on mucus and ciliary components of mucociliary clearance. J Pharm Pharmacol. 1990;42:145-51.

64. Goncharuk G. Experimental investigation of the effect of organomercury pesticides on generative function and on progeny. Hyg Sanit. 1971;36:40-4.

65. Kahn A, Atkinson A, Graham T, et al. Effects of inorganic mercury in reproductive performance of mice. Food Chem Toxicol. 2004;42:571-7.

66. Goth S, Chu R, Gregg J, et al. Uncoupling of ATP-mediated calcium signaling and dysregulated interleukin-6 secretion in dendritic cells by nanomolar thimerosal. Environ Health Perspect. 2006;114:1083-91.

67. Agrawal A, Kaushal P, Agrawal S, et al. Thimerosal induces TH2 responses via influencing cytokine secretion by human dendritic cells. J Leukoc Bio. 2007;81:474-82.

68. Ueha-Ishibashi T, Oyama Y, Nakao H, et al. Flow-cytometric analysis on cytotoxic effect of thimerosal, a preservative in vaccines, on lymphocytes dissociated from rat thymic glands. Toxicol In Vitro. 2005;19:191-8.

69. Reader M, Lines C. Decomposition of Thimerosal in aqueous solution and its determination by high-performance liquid chromatography. J Pharm Sci. 1983;72:1406-9.

70. Haley B. Mercury toxicity: genetic susceptibility and synergistic effects. Med Ver. 2005;2:535-42.

71. Humphrey M, Cole M, Pendergrass J, et al. Mitochondrial mediated thimerosal-induced apoptosis in a human neuroblastoma cell line (SK-N-SH). Neurotoxicology. 2005;26:407-16.

72. James S, Slikker W, Melnyk S, et al. Thimerosal neurotoxicity is associated with glutathione depletion: protection with glutathione precursors. Neurotoxicology. 2005;26:1-8.

73. Faure A, Grunwald D, Moutin M. Developmental expression of the calcium release channels during early neurogenesis of the mouse cerebral cortex. Eur J Neurosci. 2001;14:161322.

74. Paemeleire K, de Hemptinne A, Laeybaert L. Chemically, mechanically, and hyperosmolarity-induced calcium responses of rat cortical capillary endothelial cells in culture. Exp Brain Res. 1999;126:473-81.

75. Bull R, Marengo J, Finkelstein J, et al. SH oxidation coordinates subunits of rat brain ryanodine receptor channels activated by calcium and ATP. Am J Physiol Cell Physiol. 2003;285:C119-C128.

76. Vanlingen S, Sipma H, Missiaen L, et al. Modulation of type 1,2 and 3 inositol 1,4,5-trisphosphate receptors by cyclic ADP-ribose and thimerosal. Cell Calcium. 1999;25:10714. 
77. Jin Y, Kim D, Khil L, et al. Thimerosal decreases TRPV1 activity by oxidation of extracellular sulfhydryl residues. Neurosci Lett. 2004;369:250-5.

78. Ueha-Ishibaschi T, Oyama Y, Nakao H, et al. Effect of thimerosal, a preservative in vaccines, on intracellular $\mathrm{Ca} 2+$ concentration of rat cerebellar neurons. Toxicology. 2004;195:77-84.

79. Bull R, Finkelstein J, Humeres A, et al. Effects of ATP, $\mathrm{Mg} 2+$, and redox agents on the $\mathrm{Ca} 2+$ dependence of RyR channels from rat brain cortex. Am J Physiol Cell Physiol. 2007;293:C162-C171.

80. Faustman E, Silbernagel S, Fenske R, et al. Mechanism underlying children's susceptibility to environmental toxicants. Environ Health Perspect. 2000;108(suppl.1):13-21.

81. Mutter J, Naumann J, Schneider R, et al. Mercury and autism: accelerating evidence? Neuroendocrinol Lett. 2005;26:43946.

82. Baskin D, Ngo H, Didenko W. Thimerosal induces DNA breaks, caspase-3 activation, membrane damage and cell death in cultured human neurons and fibroblasts. Toxicol Sc. 2003;74:361-8.

83. Yel L, Brown L, Su K, et al. Thimerosal induces neuronal cell apoptosis by causing cytochrome c and apoptosisinducing factor release from mitochondria. Int J Mol Med. 2005;16:971-7.

84. Brown L, Yel L. Thimerosal induces neuronal cells via changes in the mitochondrial environment. UCI Undergrad Res J. 2003;6:7-14.

85. Parran D, Barker A, Ehrich M. Effects of thimerosal on NGF signal transduction and cell death in neuroblastoma cells. Toxicol Sci. 2005;86:132-140.

86. Mutkus L, Aschner J, Syversen T et al. In vitro uptake of glutamate in GLAST- and GLT-1-transfected mutant CHO-K1 cells is inhibited by the ethylmercury-containing preservative thimerosal. BiolTrace Elem Res. 2005;105:71-86.

87. Blaylock R. The central role of excitotoxins in autism spectrum disorders. J Amer Nutr Assoc. 2003;6:7-19.

88. Blaylock R. Interactions of cytokines, excitotoxins, and reactive nitrogen and oxygen species in autism spectrum disorders. J Amer Nutr Assoc. 2003;6:21-35.

89. Blaylock R. Chronic microglial activation and excitotoxicity secondary to excessive immune stimulation: possible factors in Gulf War Syndrome and autism. J Am Phys Surg. 2004;9:46-51.

90. Leong C, Syed N, Lorscheider F. Retrogade degeneration of neurite membrane structural integrity of nerve growth cones following in vitro exposure to mercury. Neuro Report. 2001;12:733-7.

91. Parry J. An evaluation of the use of in vitro tubulin polymerisation, fungal and wheat assays to detect the activity of potencial chemical aneugens. Mutation Res. 1993;287:23-8.

92. Wallin M, Hartely-Asp B. Effects of potencial aneuploidy inducing agents on microtubule assembly in vitro. Mutation Res. 1993;287:17-22.

93. Brunner M, Albertini S, Wurgler F. Effects of 10 known or suspected spindle poisons in the vitro porcine brain tubulin assembly assay. Mutagenesis. 1991;6:65-70.
94. Fagala G, Wigg C. Psychiatric manifestations of mercury poisoning. J Am Acad. 1992;31:306-11.

95. Taueg C, Sanfilippo D, Rowens B, et al. Acute and chronic poisoning exposures to elemental mercury. J Toxicol Clin Toxicol. 1992;30:63-7.

96. Ellingsen D, Bast-Pettersen R, Efskind J, et al. Neuropsychological effects exposure in chloralkali workers. Neurotoxicology. 2001;22:249-58.

97. James S, Cutler P, Melnyk S, et al. Metabolic biomarkers of increased oxidative stress and impared methylation capacity in children with autistic spectrum disorders. Am J Clin Nutr. 2004;80:1611-7.

98. Boris M, Goldblatt A, Galanko J, et al. Association of 5,10-methylenetetrahydrofolate reductase (MTHFR) gene polymorphisms with autistic spectrum disorders. J Am Phys Surg. 2004;9:106-8.

99. Waly M, Olteanu H, Banerjee R, et al. Activation of methionine synthase by insulin-like growth factor-1 and dopamine: a target for neurodevelopmental toxins and thimerosal. Mol Psychiatry. 2004;9:358-70.

100.Arsenijevic Y, Weiss S, Schneider B, et al. Insulin-like growth factor-1 is necessary for neural stem cell proliferation and demostrates distinct actions of epidermal growth factor and fibroblast growth factor-2. J Neurosci. 2001;21:7194-202.

101. Riaz S, Jauniaux E, Stern G, et al. The controlled conversion of human neural progenitor cells derived from fetal ventral mesencephalon into dopaminergic neurons in vitro. Brain Res Dev Brain Res. 2002;136:27-34.

102. Havarinasab S, Hultman P. Organic mercury compounds and autoimmunity. Autoimmun Rev. 2005;4:270-5.

103. Havarinasab S, Lambertsson L, Qvarnstrom J, et al. Doseresponse study of thimerosal-induced murine systemic autoimmunity. Toxicol Appl Pharmacol. 2004;194:169-79.

104. Havarinasab S, Haggqvist B, Bjorn E, et al. Immunosuppressive and autoimmune effects of thimerosal in mice. Toxicol Appl Pharmacol. 2005;204:109-21.

105. Havarinasab S, Hultman P. Alteration of the spontaneous systemic autoimmune disease in (NZB $x$ NZW)F1 mice by treatment with thimerosal (ethyl mercury). Toxicol Appl Pharmacol. 2006;214:43-54.

106. Havarinasab S, Bjorn E, Ekstrand J, et al. Dose and Hg species determine the T-helper cell activation in murine autoimmunity. Toxicology. 2007;229:23-32.

107.US. Food and Drug Administration. Department Of Health and Human Services. Centers for Biologics Evaluation and Research. Thimerosal in vaccines; http://www.fda.gov/cber/ vaccine/thimerosal.htm.

108. Clarkson T, Magos L, Myers, G. The toxicology of mercury - Current exposures and clinical manifestations. N Engl J Med. 2003;349:1731-7.

109. Steuerwald U, Weihe P, Jorgensen P, et al. Maternal seafood diet, methylmercury exposure, and neonatal neurologic function. J Pediatr. 2000;136:599-605.

110.Grandjean P, Weihe P. Neurobehavioral effects of intrauterine mercury exposure: potential sources of bias. Environ Res. 1993;61:176-83.

111.Grandjean P, Budtz-Jorgensen E, White R, et al. Methylmercury exposure biomarkers as indicators of 
neurotoxicity in children aged 7 years. Am J Epidemiol. 1999; 150:301-5.

112. Grandjean $\mathrm{P}$, Weihe $\mathrm{P}$, White $\mathrm{R}$, et al. Cognitive performance of children prenatally exposed to "safe" levels of methylmercury. Environ Res. 1998;77:165-72.

113. Courchesne E. New evidence of cerebellar and brain stem hypoplasia in autistic infants, children, and adolescents: the MR imaging study by Hashimoto and colleagues. J Aut Dev Disord. 1995;25:19-22.

114.Kemper T, Bauman M. The contribution of neuropathologic studies to the understanding of autism. Neurol Clin. 1993; 11:175-87.

115.Ritvo E, Freeman B, Scheibel A, et al. Purkinje cell counts in the cerebella of four autistic subjects: initial findings of the UCLA-NSAC autopsy research reports. Am J Psychiat. 1986;143:862-6.

116. Bailey A, Luthert P, Dean A, et al. A clinicopathological study of autism. Brain. 1998;121:889-905.

117.Ross J, Switzer R, Poston M, et al. Distribution of bismuth in the brain after intraperitoneal dosing of bismuth subnitrate in mice: implications for routes of entry of xenobiotic metals into the brain. Brain Res. 1996;725:137-54.

118.Sorensen F, Larsen J, Eide R, et al. Neuron loss in cerebellar cortex of rats exposed to mercury vapor: a stereological study. Acta Neuropathol. 2000;100:95-100.

119.Kenntner N, Tataruch F, Krone O. Heavy metals in soft tissue of white-tailed eagles found dead or moribund in Germany and Austria from 1993-2000. Environ Toxicol Chem. 2001;20:1831-7.

120.Stoev S, Grozeva N, Simeonov R, et al. Experimental cadmium poisoning in sheep. Exp Toxicol Pathol. 2003;55:309-14.

121.Piao F, Ma N, Hiraku Y, et al. Oxidative DNA damage in relation to neurotoxicity in the brain of mice exposed to arsenic at environmentally relevant levels. J Occup Health. 1995;47:445-9.

122.Sakamoto M, Kakita A, Wakabayashi K, et al. Evaluation of changes in methylmercury accumulation in the developing rat brain and its effects: a study with consecutive and moderate dose exposure throughout gestation and lactation periods. Brain Res. 2002;949:51-9.

123. Warfvinge K. Mercury distribution in the neonatal and adult cerebellum alters mercury vapor exposure of pregnant squirrel monkeys. Environmental Res. 2000;83:93-101.

124.Savolainen K, Loikkanen J, Eerikainen S, et al. Interactions of excitatory neurotransmitters and xenobiotics in excitotoxicity and oxidative stress: glutamate and lead. Toxicol Lett. 1998;102-103:363-76.

125.Nakaso K, Kitayama M, Fukuda H, et al. Oxidative stressrelated proteins A170 and heme oxygenase- 1 are differently induced in the rat cerebellum under kainate-mediated excitotoxicity. Neurosci Lett. 2000;282:57-60.

126. Olanow C, Arendash G. Metals and free radicals in neurodegeneration. Curr Opin Neurol. 1994;7:548-58.

127.Szatmari P, Paterson A, Zwaigenbaum L, et al. Autism Genome Project Consortium. Mapping autism risk loci using genetic linkage and chromosomal rearrangements. Nat Genet. 2007;39:319-28.
128. Vargas D, Nascimbene C, Krishnan C, et al. Neuroglial activation and neuroinflammation in the brain of patients with autism. Ann Neurol. 2005;57:67-81.

129.Laurence J, Fatemi S. Glial fibrillary acidic protein is elevated in superior frontal, parietal and cerebellar cortices of autistic subjects. Cerebellum. 2005;206-10.

130.Ahlsen G, Rosengren L, Belfrage M, et al. Glial fibrillary acidic protein in the cerebrospinal fluid of children with autism and other neuropsychiatric disorders. Biol Psychiat. 1993;33:734-43.

131. Herbert M. Large brains in autism: The challenge of pervasive abnormality. Neuroscientist. 2005;11:417-40.

132. Charleston $\mathrm{J}$, Bolender $\mathrm{R}$, Mottet $\mathrm{N}$, et al. Increases in the number of reactive glia in the visual cortex of Macaca fascicularis following subclinical long-term methylmercury exposure. Toxicol Appl Pharmacol. 1994;129:196-206.

133. Charleston J, Body R, Mottet N, et al. Autometallographic determination of inorganic mercury distribution in the cortex of Macaca fascicularis following subclinical long-term exposure to methylmercury and mercuric chloride. Toxicol Appl Pharmacol. 1995;132:325-33.

134. Charleston J, Body R, Boleader R, et al. Changes in the number of astrozytes and microglia in the thalamus of the monkey Macaca fascicularis following long-term subclinical methylmercury exposure. Neurotoxicology. 1996;17:12738 .

135. Kemper T, Bauman M. Neuropathology of infantile autism. J Neuropathol Exp Neurol. 1998;57:645-52.

136.Bauman M, Kemper T. The neuropathology of the autism spectrum disorders: what have we learned? Novartis Found Symp. 2003;251:112-22.

137. Buxhoeveden D, Semendeferi K, Buckwalters J, et al. Reduced minicolumns in the frontal cortex of patients with autism. Neuropathol Appl Neurobioly. 2006;32:483-91.

138.Environmental Working Group. Overloaded? New science, new insights about mercury and autism in susceptible children. Washington, D.C.: EWG Action Found; 2004.

139. McGinnis W. Oxidative stress in autism. Altern Ther Health Med. 2004;10:22-36.

140. Chauhsun A, Chauhsun V. Oxidative stress in autism. Pathophysiology. 2006;13:171-81.

141.Kern J, Jones A. Evidence of toxicity, oxidative stress, and neuronal insult in autism. J Toxicol Environ Health, Part B. 2006;9:485-99.

142. Maya L, Luna F. El timerosal y las enfermedades del neurodesarrollo infantil. An Fac Med Lima. 2006;67:25574.

Manuscrito recibido el 20 de agosto de 2007 y aceptado para publicación el 26 de setiembre de 2007.

\section{Correspondencia:}

Sr. Jonny Laurente Gómez.

Jr. Los Nogales 618, Coop. Universal III Etapa

Santa Anita. Lima 43, Perú.

Correo-e: jonnylg@hotmail.com 